\title{
Nanobelt Mission Accomplished: A Loop of 12 Fused Edge-Sharing Benzenes
}

\section{Category}

Synthesis of

Materials and

Unnatural Products

\section{Key words}

aryl-aryl coupling

Wittig reaction

carbon nanobelt<smiles>O=Cc1cc(Br)c(C(Br)Br)cc1Br</smiles><smiles>COC(OC)c1cc(Br)c(Br)cc1Br</smiles>

2

1. 2, $\mathrm{Ph}_{3} \mathrm{P}$

THF-MeOH, reflux, $3 \mathrm{~h}$

2. 1, $t$-BuOK

THF, r.t., $25 \mathrm{~min}$

3. $(\mathrm{MeO})_{2} \mathrm{POH}$

DIPEA, r.t., $1 \mathrm{~h}$

$80 \%$ yield

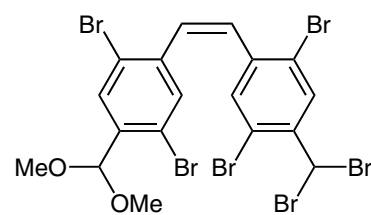

3<smiles>COC(OC)c1cc(Br)c(/C=C\c2cc(Br)c(C(Br)Br)cc2Br)cc1Br</smiles>

3

1. $\mathrm{Ph}_{3} \mathrm{P}$

THF-MeOH, reflux, $5 \mathrm{~h}$

2. $\mathrm{HCl}$

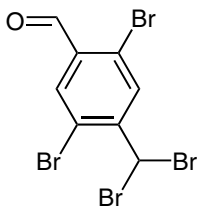

1. 3, $\mathrm{Ph}_{3} \mathrm{P}$

THF-MeOH, reflux, $3.5 \mathrm{~h}$

\section{2. $1, t$-BuOK}

THF, r.t., $1 \mathrm{~h}$

1

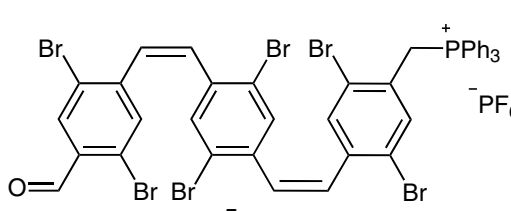

5

$\mathrm{KPF}_{6}$

$86 \%$ yield based on 3

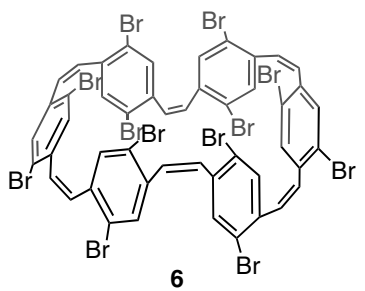

$\underset{\mathrm{DMF}, 70^{\circ} \mathrm{C}, 15 \mathrm{~min}}{\stackrel{\mathrm{Ni}(\operatorname{cod})_{2}, 2,2^{\prime} \text {-bipyridyl }}{\longrightarrow}}$

$1 \%$ yield
6

$\mathrm{CH}_{2} \mathrm{Cl}_{2}, 0^{\circ} \mathrm{C}$ to r.t., 80 min

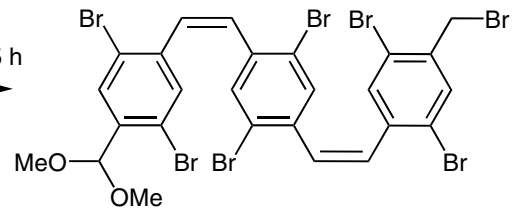

4

$36 \%$ yield
Significance: The synthesis of a fully fused carbon nanobelt $(7)$ - a belt segment of a $(6,6)$ carbon nanotube - has been a long-lasting goal in materials science. Segawa, Itami, and co-workers have now reported on the successful bottom-up synthesis of such a carbon nanobelt, a closed loop of 12 fully fused edge-sharing benzene rings. The synthesis starts with several consecutive Wittig reactions. In the final step, a Ni(cod) $)_{2}$-mediated aryl-aryl coupling reaction prompts the formation of the new fully fused arene system.

SYNFACTS Contributors: Timothy M. Swager, Lukas Zeininger Synfacts 2017, 13(07), 0697 Published online: 19.06.2017 DOI: $10.1055 / \mathrm{s}-0036-1590570$; Reg-No.: S05417SF
Comment: The authors studied in detail the optoelectronic and structural properties of this 'shortest armchair carbon nanotube'. Besides verifying the rigid cylindrical shape of this carbon nanobelt through X-ray crystallography, its photophysical characterization combined with theoretical calculations confirmed the structural rigidity of this fully conjugated arene system. The synthesis of this belt of 12 edge-sharing benzene rings may pave the way towards a precisely controlled singlechirality bottom-up synthesis of $(6,6)$ carbon nanotubes. 